\title{
The consequences of missing appendicitis during pregnancy
}

\author{
Papa Dasari, Dilip Kumar Maurya \\ Obstetrics and Gynaecology, JIPMER, Puducherry, Puducherry, India \\ Correspondence to Professor Papa-Dasari, dasaripapa@gmail.com
}

\begin{abstract}
Summary
A 23-year-old second para was admitted for severe anaemia with abdominal distension in the immediate puerperal period following a preterm delivery. She suffered from acute abdominal pain 3 days back (at 32 weeks of gestation) and was evaluated in the emergency medical department for appendicitis/cholecystitis. Abdominal ultrasound was found to be normal and she received antacids for her pain abdomen. Clinical examination the day after delivery revealed abdominal distension, guarding and rigidity. Ultrasonography revealed a normal puerperal uterus with free fluid in the abdomen which on diagnostic aspiration was pus. Emergency laparotomy showed acute suppurative appendicitis with perforation. Appendecectomy with peritoneal lavage was done. Her postoperative period was stormy with high febrile spikes and evaluation confirmed septicaemia. The organism grown on postoperative blood culture and cervical swab culture was Enterococcus fecalis sensitive to vancomycin and she received the same for 10 days and recovered.
\end{abstract}

\section{BACKGROUND}

Acute appendicitis though one of the common surgical emergencies, is rare during pregnancy and often the presentation is atypical.

If the treatment is delayed it can lead to severe morbidity and mortality of mother and foetus.

Missed diagnosis can be one of the claims of negligence.

\section{CASE PRESENTATION}

A 23-year-old para 2 was admitted on the first post natal day to the emergency obstetrics department with distension of abdomen and pain abdomen since delivery. She had preterm delivery the day before, at $32+5$ weeks and the neonate weighing $1.75 \mathrm{~kg}$ was admitted to neonatal intensive care unit (NICU).

She gave history of giddiness and palpitations and excessive bleeding following delivery and was treated with oxytocics and one unit of compatible packed cell transfusion.

Her antenatal history revealed that she attended the emergency medical department 3 days ago with pain in abdomen and vomiting and was examined and found to have a pulse rate of $110 / \mathrm{min}$ and blood pressure (BP) of 110/60 mm Hg. Abdominal tenderness could not be elicited and she was advised ultrasonography (USG) to rule out cholecystitis/appendicitis. USG done by radiologist reported a single live intrauterine pregnancy of 33 weeks with normal liver, gall bladder, spleen and kidneys of the mother. She was started tablet omperazole to be taken for 5 days and was sent home. The medication did not relieve her symptoms and she delivered a preterm baby in a nearby primary health centre and was referred to this institute for NICU care.

Obstetric history: She had a full term normal delivery without any complications 2 years back.
Family history: Nil significant.

On examination, she was afebrile, had moderate pallor, with a pulse rate of $120 / \mathrm{min}, \mathrm{BP} 90 / 70$. She was tachypneic but respiratory system was clear, abdomen was distended with diffuse tenderness. with minimal guarding and rigidity. Perineum was intact and bleeding per vaginum was within normal limits and uterus was felt to be 18 weeks size and contracted firmly.

USG showed a puerperal uterus with empty cavity with free fluid collection anterior to it and also in Pouch of Douglas (figure 1). Diagnostic aspiration under USG guidance revealed pus. A provisional diagnosis of peurperal sepsis with peritonitis with pyoperitoneum was made and an emergency laparotomy was carried out. There was 2 litres of foul smelling pus in the peritoneal cavity. Uterus was intact and adnexae were covered by flakes of pus. Intestines were explored which revealed an inflamed appendix with a $0.5 \mathrm{~cm}$ fecolith on its surface. Hence surgeons were called and appendicectomy was performed. Saline peritoneal lavage was done and two drains were kept, one in peritoneal cavity and the other in the pelvis. She was continued on antibiotics viz: ceftriaxone, amikacin and metronidazole which were started preoperatively. Postoperatively she had febrile spikes up to $102^{\circ} \mathrm{F}$ (figure 2A,B) for 10 days and suffered from paralytic ileus for 7 days. She developed blisters on the thighs and external genitalia on fifth postoperative day and dermatology consultation opined it to be contact dermatitis to savlon. However, the blister fluid grew Candida albicans which was sensitive to fluconazole.

Antibiotics were changed to magnex (cefoperazone + sulbactam) but there was no improvement. Later she was treated with injection vancomycin for 10 days according to blood culture which showed $E$ fecalis sensitive only to vancomycin. She was discharged after 3 weeks of surgery. 


\section{INVESTIGATIONS}

\begin{tabular}{|c|c|}
\hline \multicolumn{2}{|l|}{ Day of admission } \\
\hline Haemoglobin & $7.2 \mathrm{~g} \%$ \\
\hline \multicolumn{2}{|l|}{ Preoperative } \\
\hline Pus c/s & Sterile \\
\hline Blood c/s & Sterile \\
\hline Cervical swab c/s & Sterile \\
\hline \multicolumn{2}{|l|}{ Day of surgery } \\
\hline Blood sugar & 88 mg\% \\
\hline Blood urea & 62 mg\% \\
\hline Serum creatinine & $0.8 \mathrm{mg} \%$ \\
\hline $\mathrm{Na}+$ & $138 \mathrm{meq} / \mathrm{l}$ \\
\hline $\mathrm{K}+$ & $5 \mathrm{meq} / \mathrm{l}$ \\
\hline INR & 1.45 \\
\hline Haemoglobin & $12 \mathrm{~g} \%$ \\
\hline HIV & Negative \\
\hline \multicolumn{2}{|l|}{ Postoperative } \\
\hline Haemoglobin & $11 \mathrm{~g} \%$ \\
\hline Total lung capacity & 12000 \\
\hline $\mathrm{N}$ & 60 \\
\hline $\mathrm{L}$ & 35 \\
\hline Erythrocyte sedimentation rate & $55 \mathrm{~mm}$ \\
\hline Blood urea & 19 mg\% \\
\hline Serum creatinine & $0.5 \mathrm{mg} \%$ \\
\hline $\mathrm{Na}$ & 134 \\
\hline K & 3.3 \\
\hline Blood sugar & 69 mg\% \\
\hline X-ray chest & $\mathrm{P} / \mathrm{A}$ \\
\hline Pleural fluid & sugar 61 mg\% \\
\hline Protein & $1.7 \mathrm{~g} \%$ \\
\hline Liver function test & Normal \\
\hline Cervical swab c/s & $\begin{array}{l}\text { E fecalis sensitive to gentamicin and } \\
\text { vancomycin }\end{array}$ \\
\hline Blood culture & Enterococus sensitive to vancomycin only \\
\hline Wound swab c/s & Acenetobacter baumani resistant to all \\
\hline Blister fluid c/s & $\begin{array}{l}C \text { albicans sensitive to fluconazole and } \\
\text { amphotercine } B\end{array}$ \\
\hline HPE & Acute suppurative appendicitis \\
\hline
\end{tabular}

HPE, Histopathological examination; INR, international normalized ratio

\section{DIFFERENTIAL DIAGNOSIS}

- Antenatal period - acute cholecystits.

- Preoperative - peurperal sepsis with peritonitis.

- Postoperative - septicaemia secondary to peurperal sepsis?

- Acute suppurative appendicitis.

- Final diagnosis - septicaemia due to perforated acute suppurative appendicitis.

\section{TREATMENT}

- Preoperative blood transfusion for anaemia.

- Presurgical - diagnostic aspiration and broadspectrum antibiotics including cephalosporins.

- Surgical treatment-exploratory laparotomy and appendicectomy and peritoneal lavage with insertion of pelvic and peritoneal drains.

- postoperative - treatment for paralytic ileus and septicaemia and pleural aspiration for pleural effusion.

\section{OUTCOME AND FOLLOW-UP}

Prolonged morbidity: febrile morbidity due to septicaemia and sequalae.

Follow-up at 6 weeks: wound healed well and she gained $2 \mathrm{~kg}$ weight.

\section{DISCUSSION}

Acute appendicitis, one of the most common surgical emergencies worldwide (one in 1500 pregnancies), is often misdiagnosed at initial presentation even in recent times. ${ }^{1}$ Incidence of misdiagnosis increases during pregnancy because of the physiological changes that occur during pregnancy. There is a reluctance on the part of the treating surgeon to subject the patients to laparotomy even when appendicitis is suspected because the appendix is reported to be normal in approximately $20 \%$ of those who undergo laparotomy for this reason. ${ }^{2}$ Delaying laparotomy can result in complications including risk of death and subsequent liability for negligence. The risks are more during pregnancy to the mother as well as the foetus. The major causes of morbidity and mortality are perforation and gangrene and the reasons leading to this are delayed presentation, fulminant disease, misdiagnosis and failure to accept medical therapy. ${ }^{3}$ This is because the symptoms of appendicitis mimic symptoms of normal pregnancy namely, anorexia, nausea, vomiting and abdominal discomfort.. ${ }^{4}$ Various diagnostic entities that were considered and treated on initial presentation were malaria, amoebiasis, colitis, pelvic inflammatory disease and urinary tract infection. ${ }^{1}$

A recent study which analysed 102 pregnant women with acute appendicitis revealed pain in abdomen as the commonest $(100 \%)$ complaint and vomiting as the next common complaint (87\%). The most common physical finding was abdominal tenderness and rebound tenderness and only $50 \%$ had fever. ${ }^{4}$ The present case also complained of pain abdomen and vomiting but the physician could not elicit abdominal tenderness at the initial presentation during the antenatal period. Adler's sign has been suggested to differentiate acute appendicitis from pain arising from uterine and adenexal origin if rebound abdominal tenderness could be elicited. ${ }^{4}$ Few studies report that the most common symptom of appendicitis during pregnancy is also similar to non-pregnant state that is right lower quadrant pain regardless of the gestational age. ${ }^{5} 6$ But the clinical signs such as psoas test, obturator test and Rovsing's sign were found to be postive less often during pregnancy.

The management of ruptured appendicitis during pregnancy should be surgical to prevent morbidity and mortality but case reports of successful medical management are on record. ${ }^{8}$ A case control study which aimed to determine the risk factors associated with outcome of pregnancy found a statistically significant difference in complications between the cases with perforated appendix and non-perforated appendix. The interval between the onset of symptoms and the time of operation is the only variable that was independently associated with the appendiceal perforation. Presence of perforation was the only predictive factor for maternal morbidity and the fetal mortality was $8 \%$ in this study. ${ }^{9}$ A large review from 1975 to 2005 also found the risk of complications to increase with the delay in surgery. The delay in diagnosis was found to increase the risk of perforation, infection, preterm labour and foetal and maternal loss. ${ }^{10}$ Early surgical intervention was found to result in good maternal and fetal outcome with $18 \%$ appendiceal perforation with a negative laparotmy rate of $9 \% .{ }^{11}$

It is clear from the literature review that accurate diagnosis is essential to reduce the foetal as well as maternal 


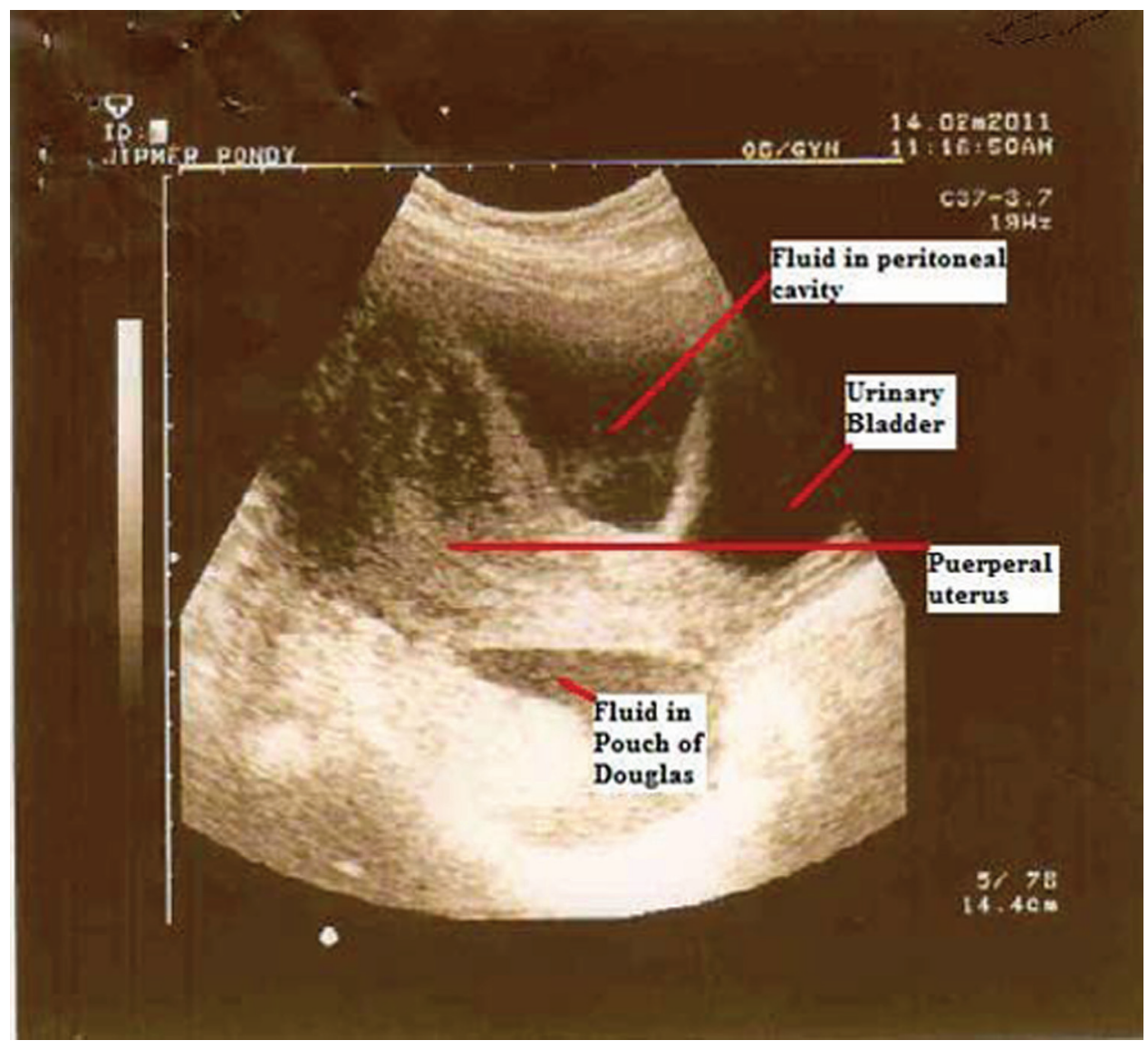

Figure 1 Abdominal USG the day after admission shows the puerperal uterus which was empty and presence of fluid posteriorly in the pouch of douglas and anteriorly above the bladder.
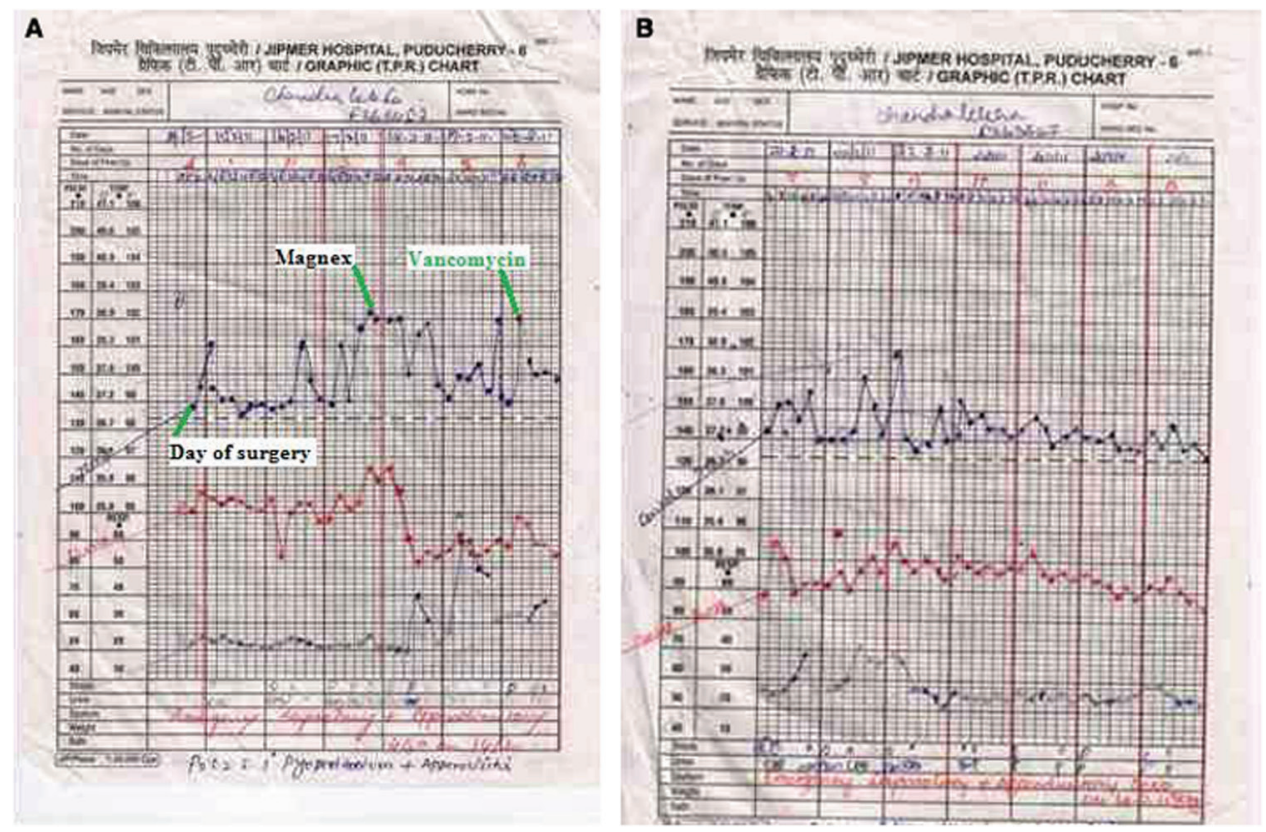

Figure 2 (A) Temperature chart from the day of laparotomy. (B) Temperature chart after starting injection vancomycin.

morbidity and mortality and the clinical symptoms and signs are not very reliable, In this context additional methods to add to or increase the accuracy of clinical diagnosis were investigated. Abdominal USG along with clinical features was found to result in a negative laparotomy rate of $5.5 \%$ without any foetal or maternal loss. ${ }^{12}$ The graded compression ultrasonogram was reported to be a better technique but its use is also limited because of 
difficulty in compressing the caecum and difficulty in visualisation of normal appendix during pregnancy. A study undertaken to find out the negative laparotomy rate when imaging was supplemented to clinical examination during pregnancy concluded that USG followed by CT to be superior to decrease the negative laparotomy rate than clinical examination alone or USG alone. ${ }^{13}$ CT is usually avoided during pregnancy because of the risk of radiation to the maternal gonads and the foetus. The role of MRI was assessed recently by various authors and it was found to be superior to CT and USG in its greater ability of visualisation of normal appendix in as high as $87 \%$ of cases. Visualising normal appendix on MRI excludes the diagnosis of appendicitis and thus decrease the negative laparotomy rates. ${ }^{14}$ The findings diagnostic of appendicitis on MRI are an appendiceal diameter of $6 \mathrm{~mm}$ or more and periappendiceal inflammation. The lumen appears to have high signal intensity on T2 weighted fat suppressed images and low signal intensity on T1 weighted images. The wall appears as hypointense on T1 weighted images and slightly hyperintense on T2 weighted images. The inflammatory changes surrounding the appendix appear as high signal intensity on T2 weighted fat suppressed images and low signal intensity on T2 weighted images. With these criteria Cobben and colleagues could diagnose and rule out acute appendicitis during pregnancy with $100 \%$ accuracy. $^{15}$

A study aimed to find out the bacteriology of appendicitis during and after surgery found predominantly, aerobic organisms in early cases and a mixed pattern of aerobic and anaerobic organisms in late cases. Bacteroides fragilis and Escherichia coli were the most common organisms isolated. A combination of metronidazole and clindamycin were found to be effective for anaerobic coverage and an aminoglycoside or a cephalosporin met adequate coverage of aerobes and the best single drug to cover both aerobes and anaerobes was moxalactam. The infection was due to endogenous contamination and the infection spread through the appendicular wall as the disease progressed. ${ }^{16}$ The present case developed widespread complications due to septicaemia after surgery, possibly because of endogenous contamination at surgery. The blisters due to fungal infection may be explained by prolonged antibiotics and immunosupression due to sepsis. Though in many cases with septicaemia due to appendicitis the blood culture may not grow organisms, in this patient the endogenous organism $E$ fecalis was grown in blood and also in cervical swab. The evidence for the endogenous source is strengthened by the fact that the preoperative blood and cervical swab cultures were negative in this case.

In conclusion, it can be said that it is easy to miss the diagnosis of appendicitis during pregnancy when USG is advocated and MRI should be the imaging modality of choice to diagnose or rule out the same. When appendicitis is missed during pregnancy it can present in the immediate postnatal period with septic complications such as peritonitis due to perforation. This case illustrates the development of septicaemia and other complications that follow the surgery for perforated appendicitis and their life threatening nature.

\section{Learning points}

It is necessary to hospitalise a woman suspected of acute appendicitis during pregnancy

- Misdiagnosis is common during pregnancy because of atypical clinical presentation

- It is important to subject the pregnant woman suspected of acute appendicitis to sophisticated investigations like CT and MRI so that delay in arriving at diagnosis can be avoided.

- Delay in diagnosis leads to perforation of appendix and severe life threatening complications.

- Early surgical intervention is life saving.

\section{Competing interests None.}

Patient consent Obtained.

\section{REFERENCES}

1. Doumi EA, Abdelrahman IH. Acute appendicits: still a missed diagnosis in El Obeid, Western Sudan, Sudan. JMS 2007;2:7-9.

2. Paulson EK, Kalady MF, Pappas TN. Suspected appendicits. N Engl J Med 2003;348:236-42.

3. Edino ST, Mohamed AZ, Ochicha 0, et al. Appendicitis in Kano, Nigeria: a five year review of pattern, morbidity and mortality. Ann of African medicine 2004; $3: 38-41$.

4. Yan Z, Yang-yu Z, Jie Q, et al. Diagnosis of appendicitis during pregnancy and perinatal outcome in late pregnancy. Chin Med J 2009;122:521-4.

5. Mourad J, Elliott JP, Erickson L, et al. Appendicitis in pregnancy: new information that contradicts long-held clinical beliefs. Am J Obstet Gynecol 2000;182:1027-9.

6. Hodjati $\mathbf{H}$, Kazerooni T. Location of the appendix in the gravid patient: a re-evaluation of the established concept. Int J Gynaecol Obstet 2003;81:245-7.

7. Chawla S, Vardhan S. Jog BSS.Appendicitis during pregnancy. MJAFI 2003;59:212-15.

8. Brett CY, Benjamin DH, Deborah L, et al. Medical management of ruptured appendicitis during pregnancy. Obstet Gynecol 2009;114:453-6.

9. Yilmaz HC, Akqun Y, Bac B, et al. Acute appendicitis in pregnancy-risk factors associated with principal outcomes:a case control study. Int J Surg 2007:5:192-7.

10. Pastore PA, Loomis DM, Sauret J. Appendicitis in pregnancy. JABFM 2006; 19:621-6.

11. Raja KS, Januja BN, lqbal J. Appendicitis in pregnancy. Rawal Med. J 2003;28:52-5.

12. Asghar MT, Cheema KM, Choudhary MS. Acute appendicitis in pregnancy. http://www.sims.edu.pk/esculapio.html (accessed on 26th june 2011).

13. Wallace CA, Petrov MS, Soybel DI, et al. Influence of imaging on the negative appendectomy rate in pregnancy. J Gastrointest Surg 2008;12:46-50.

14. Pedrosa I, Lafornara M, Pandharipande PV, et al. Pregnant patients suspected of having acute appendicitis: effect of MR imaging on negative laparotomy rate and appendiceal perforation rate. Radiology 2009;250:749-57.

15. Cobben LP, Groot I, Haans L, et al. MRI for clinically suspected appendicitis during pregnancy. AJR Am J Roentgenol 2004;183:671-5.

16. Lau WY, Teoh-Chan CH, Fan ST, et al. The bacteriology and septic complication of patients with appendicitis. Ann Surg 1984;200:576-81. 


\section{BMJ Case Reports}

This pdf has been created automatically from the final edited text and images.

Copyright 2011 BMJ Publishing Group. All rights reserved. For permission to reuse any of this content visit http://group.bmj.com/group/rights-licensing/permissions.

BMJ Case Report Fellows may re-use this article for personal use and teaching without any further permission.

Please cite this article as follows (you will need to access the article online to obtain the date of publication).

Dasari P, Maurya DK. The consequences of missing appendicitis during pregnancy. BMJ Case Reports 2011;10.1136/bcr.05.2011.4185, date of publication

Become a Fellow of BMJ Case Reports today and you can:

- Submit as many cases as you like

- Enjoy fast sympathetic peer review and rapid publication of accepted articles

Access all the published articles

- Re-use any of the published material for personal use and teaching without further permission

For information on Institutional Fellowships contact consortiasales@bmjgroup.com

Visit casereports.bmj.com for more articles like this and to become a Fellow 